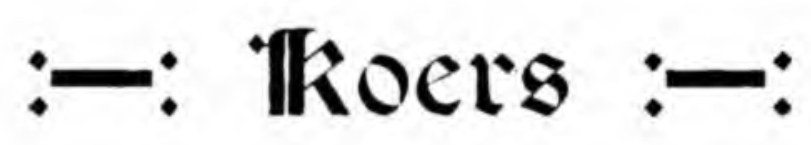

TWEEMAANDELIKSE TYDSKRIF

\begin{tabular}{lll}
\hline Jaargang XXIV & FEBRUARIE 1957 & No. 4 \\
\hline
\end{tabular}

\title{
Enkele Gedagtes oor die Calvinistiese Sosiologie en Geskiedenisfilosofie
}

Synde nòg sosioloog nòg historicus nòg filosoof skryf ek oor bogenoemde sake as belangstellende toeskouer met die bedoeling om die betrokke vakkundiges op te wek om vanuit hulle vakgebiede meer hulp te bied aan die regs- en die staatsleer, soos prof. $H$. G. Stoker reeds goedgunstig gedoen het deur kommentaar te lewer op die eerste ontwerp van hierdie artikel, soos aan my op my versoek gerig.

Soos bekend vertoon die Calvinistiese filosofie teenswoordig verskillende nuanses soos o.a. deur prof. Stoker enige jare gelede uiteengesit voor 'n kongres van wysgere te Pretoria. Op die oomblik is ek veral geinteresseerd in die teëstelling tussen prof. Stoker en prof. Dooyeweerd, waaroor onlangs geredeneer is deur prof. Stoker en dr. Taljaard in Koers, na aanleiding van die etiese grondprobleem.

Hieruit en uit bogenoemde kommentaar van prof. Stoker blyk dit dat prof. Stoker hom van prof. Dooyweeerd veral in die volgende opsigte wat vir my huidige doel belangrik is, distansieer. 
Stoker sien hiervolgens die sedelike nie, soos Dooyeweerd, net as ' $n$ funksie nie en die religieuse nie as sentraal nie. Boondien beskou hy in die algemeen die gelding van die sentrum-funksie-skema van Dooyeweerd as beperk en nie fundamenteel kosmologies nie. Ook ander modaliteite is vir hom meer as net funksioneel. Hy meen selfs dat die sentrum-funksieskema van Kantiaans-humanistiese oorsprong is. Dit is wesenlik 'n antroposentriese of liewer Christo-antroposentriese opvatting van 'n deur God geskape en aan sy wetsorde onderworpe kosmos.

Daarteenoor vind hy in die kosmos wel 'n intrinsieke eenheid in die samehang van die radikale verskeidenheid, 'n eksintrieke eenheid in die kreatuurlikheid van die geheel, en 'n kosmies-transsendente eenheidsentrum in God: 'n kosmies-immanente sentrum in die sin van Dooyeweerd kan hy dus nie aanvaar nie.

Stoker onderskei verder drieëlei konsentriese verhoudinge van God tot die kosmos: eers die godsdienstige in enger sin (Dooyeweerd noem dit die religieus-pistiese), dan die ruimere religie (Dooyeweerd noem dit die religieus-kulturele), en eindelik die teale, waarin ook alles buite die mens Godbetrokke is.

Vanuit sy so genoemde fanero-kritiese metode sien hy die werklikheid nie net wetsmodaal en subjektief-struktureel soos Dooyeweerd nie, maar in verskillende kosmiese dimensies, nl, van modaliteite, individuele en sosiale strukture, gebeurtenisse (waaronder tyd) en waardes.

Vir ons van besondere belang is dat Stoker nie alle werklikheid deur funksionele modaliteite laat bepaal nie, dat hy ook andersoortige en met name dinamiese kosmiese dimensies erken, en boondien waardes, waaroor later meer.

As ons dan die hooftrekke van Dooyeweerd se Wysbegeerte van die Wetsidee as bekend mag veronderstel, wil ek nou oorgaan tot 'n kort skets van sy opvattinge omtrent die menslike samelewing en geskiedenis, met die reaksies van Stoker daarop en enkele kritiese opmerkinge van myself, om af te sluit met meer positiewe wenke ten opsigte van die betrokke wetenskappe.

Daar is volgens hom in hierdie verband eers die mens en mensheid in onderskeiding van die ryke van dooie stof, plante en diere. Die mens leef in, maar transsendeer alle modaliteitswette; die samelewing van mense word ook beheer deur alle wetmatighede. blykbaar ook deur dié van omgang 
en verkeer, wat soms deur Dooyeweerd ook die sosiale genoem word. So word gesê dat daar in die menslike samelewing allereers die onderskeiding is van gemeenskaps- en maatskaps-verhoudinge in onverbreeklike korrelasie, primêr gekwalifiseer deur die sosiale omgangsaspek. Georganiseerde gemeenskappe word verbande genoem en hulle is van oorsprong if maatskaplik van karakter ò institutêr, m.a.w. berus op vrye aansluiting of ingeborenheid van die lede.

Alle samelewingsvorme is met mekaar vervleg in ontstaan en bestaan deur die so genoemde enkapsis. Maar elkeen het soevereniteit in eie kring, wat bepaal word deur sy eie ingeskape struktuurwet berustende op 'n tipiese verhouding tussen ' $n$ leidende en funderende funksie.

Die leidende funksie word ook die interne bestemmingsfunksie genoem en moet onderskei word van in die natuurlike orde gegronde doeleindes waaraan 'n samelewingsverhouding diensbaar is, en van die subjektiewe doelstellinge van hulle wat in hierdie verhoudinge staan.

'n Winkelbedryf is bv. na die interne sy gekarakteriseer as 'n deur die ekonomiese ondernemingsfunksie gekwalifiseerde arbeidsgemeenskap op die grondslag van 'n magsorganisasie van die kapitaal. Na die eksterne maatskapsy daarenteen is dit gerig op verkoop aan die publiek. In die doelstelling van die oprigters weer is die eintlike werkverband slegs middel.

In die samelewingstrukture onderskei hy o.a. radikaal-tipes, stam-tipes, elementêre tipes en ook variabiliteitstipes (vanweë enkaptiese vervlegting met ander strukture).

Daar word ook onderskei tussen ryke van die eerste orde en diè van die tweede orde. Onder laasgenoemde word verstaan ,diegene, welker radicaal-type in eenzijdige afhankelijkheid betrokken is hetzij op een rijk van eerste orde, hetzij onmiddellijk op den mens". Hieronder val ook die verskillende radikaaltipes van menslike samelewingstrukture. Die mens self is van primêre werklikheidsorde. Dooyeweerd verwerp egter die ontologiese en sosiologiese individualisme sowel as beide soorte universalismes.

Van die menslike gemeenskappe is sommige verder in die natuur gefundeer en ander in die historie.

Die wetenskap wat nou die struktuurtipes van menslike samelewing, soos bepaal deur die kosmiese modaliteite, as 'n totaliteit bestudeer, is die wysgerige sosiologie. Dit is geen vakwetenskap nie en kan dus nie op een 
modaliteit konsentreer nie. Dooyeweerd glo nie aan 'n formele sosiologie as vakwetenskap nie.

Die sosiologie verval egter wel in twee afdelinge nl. (a) die wysgerige, wat die konstante strukture ondersoek wat aan die samelewing ten grondslag lê, en (b) die positiewe, wat die variabele vorme ondersoek waarin hierdie strukture hulle verwerklik.

Die mens het as sodanig 'n persoonlike vryheidsfeer en fungeer tegelykertyd in 'n veelheid van gemeenskaps- en maatskapsverhoudinge, wat elk beperk word deur sy eie soevereiniteit in eie kring. Alleen die onsigbare kerk of gemeenskap van die heiliges, wat bo die tyd verhewe is, is universeel.

Deur een van Dooyeweerd se leerlinge word dit só gestel dat die sosiologie is die wetenskap van die dinamiese strukturele orde van die menslike samelewing en die daarin handelende en aanpassende mens.

Dit hoort saam met die wysgerige antropologie en psigologie tot die wysbegeerte, omdat dit van die werklikheid nie funksioneel abstraheer nie maar struktureel, deurdat hierdie wetenskappe ,uit de context van het volle leven individuele structuren, structurele individualiteiten afzonderlijk stellen, uiteenstellen en deze als individualiteiten onderzoeken naar eigen aard en structuur." (N.B. hierdie psigologie bestudeer die aktlewe as geheel en nie net die psigiese modaliteit nie).

Wat betref die sg. formele sosiologie, maak Dooyeweerd êrens die volgende interessante opmerking: ,.Men kan hoogstens zeggen, dat de menselijke samenleving een bepaald aspect vertoont, dat tot nog toe niet door een bijzondere vakwetenschap als eigen veld van onderzoek in beslag is genomen, t.w. het omgangsaspect. dat door een eigen sfeer van normen, dié van beleefdheid, fatsoen. hoffelijkheid, mode, tact, gezellingheid enz. wordt beheerst." Maar dit wil hy nie sosiologie noem nie, hoewel die aspek self tog sosiaal genoem word.

Laat ons dan nou aanneem dat die menslike samelewing as geheel in sy verskillende strukture deur die sosiologie ondersoek word en dit geen modale bepaaldheid het nie, hoewel strukture self in modaliteite gefundeer is, dan kom die vraag op wat sy verhouding is tot die geskiedwetenskap, want die probleme van die kosmologie en die primêre-kosmiese ryke soos stof plant en dier wil ons nou maar daar laat, behalwe net deur daarop te wys dat hier ook geen modaal-abstraherende wetenskappe. soos chemie, bio- 
logie, psigologie, ens. die septer sal kan voer nie, net so min as bv. ekonomie en regswetenskap in die sosiologie.

Dit is tog wel eienaardig gesteld met die geskiedenis. Gesê word deur Dooyeweerd c.s. dat ons onderskeid moet maak tussen geskiedenis self en die historikale modaliteit, en dat laasgenoemde deur die geskiedwetenskap bestudeer word. Maar dan hoor ons tog weer dat die reg ' $n$ historiese aspek het en die ekonomie ens.; maar die juridiese kan geen ekonomiese aspek hê of omgekeerd nie, want die modaliteite is soeverein in eie kring. Is die geskiedenis van die reg dan maar ' $n$ historiese analogie in die juridiese?

Onder die historiese of historikale word verstaan die werklikheidsaspek van vrye beheersende vorming of vrye beheersing. Maar is daar hiervan al 'n vakwetenskap ontwikkel, meer as van die so genoemde modaliteit van omgang en verkeer?

Die geskiedwetenskap soos ons dit ken, lyk meer na 'n totaalwetenskap van menslike samelewing, soos die sosiologie volgens bo-aangeduide bepaling: dit is as 't ware die sosiologie in beweging of ontwikkeling.

Moontlik sou dit ook soos die sosiologie onderskei kan word in ' $n$ wysgerige en positiewe geskiedwetenskap. Tog word dit as 'n modale vakwetenskap gesien.

Voordat ons verder hierop ingaan. gee ons egter nou eers aandag aan prof. Stoker se reaksies op bogenoemde beskouinge in sy private kommentaar, aan my gerig, soos aan die begin vermeld.

Vir hom is die sosiale beslis geen modale kring nie, maar 'n horisontale struktuurprinsipe wat tuishoort in die dimensie van individuele en sosiale strukture, wat self ook 'n vertikale struktuurprinsipe deelagtig is deur hul verbondenheid aan die rangorde van modaliteite. Die sosiaalstrukturele band kom ook voor in die laer ryke, maar veral intensief en ekstensief by die mens as strukturele verbondenheid in eie-soortige geheel-eenheid van individuele struktureel-bepaalde mense. Elke sosiale geheel het 'n eie aard. Ook die historiese beskou Stoker nie as 'n modaliteit nie, maar dit bring hy tuis in die dimensie van gebeurtenisse.

Elke sosiale struktuur gryp met sy bestemmings- en funderingsfunksies op die modaliteite terug en met sy historiese ontstaan, vorming en voortgang op die dimensie van gebeurtenisse; d.w.s. elke sosiale struktuur het drie bepalings: bestemming. fundering en dinamiek of historie. So hia 
'n volk 'n sedelike bestemming, 'n biotiese fundering en 'n groei-dinamiek; en 'n staat ' $n$ juridiese bestemming, 'n territoriale fundering en 'n magsvormingsdinamiek, ens. Maar bloot maatskaplike instellinge, soos ingestel deur die sosiale strukture, het slegs twee bepalings, n.l. bestemmingsfunksie en historie, maar geen funderingsfunksie nie, soos bv. 'n skool of 'n bedryf.

Die aktuele teleologie val ook volgens Stoker onder die dimensie van die gebeurtenisse, waaronder die historiese. En dit geld ook vir alle ryke van die werklikheid, maar by die mens is daar behalwe 'n eksterne doel en doelmatigheid en doelbepaaldheid ook verantwoordelike doelstelling.

Die dimensie van waardes is in dié van gebeurtenisse gefundeer, laasgenoemde in dié van strukture en die strukture weer in dié van modaliteite. Daarom is daar naas modale retro- en antisipasies, ook retro- en antisipasies tussen die dimensies.

Vakwetenskappe word onderskei volgens die gesigspunte van elk van die vier dimensies en nie slegs modaal nie. Sosiologie bv. is nie modaal nie, maar struktureel bepaal; opvoedkunde nòg modaal, nòg struktureel, maar wel onder die dimensie van gebeurtenisse. Maar altyd is daar ook verbondenheid met ander kosmiese dimensies. Boondien is die werklik, konkreet bestaande skepsele altyd meer as die som van kosmiese dimensies waaronder hulle gevat kan word. Die dimensionele siening bly altyd 'n abstraksie en vakwetenskaplik. Sosiologie as wetenskap van sosiale strukture is ook vakwetenskaplik in daardie bepaalde dimensie, soos die historiewetenskap in dié van gebeurtenisse. As alleen modale wetenskappe vakwetenskaplik is, dan moet al die res wel tot die wysbegeerte behoort! Maar dit neem Stoker juis nie aan nie. Omgekeerd is nie alle totaliteitswetenskappe wysgerig nie, bv. die teologie. Ook sosiale omgang en verkeer is nie modaal bepaal nie, maar hoort tuis in die dimensie van gebeurtenisse met dimensionele retrosipasies op die strukturele dimensie.

Wat die geskiedenis meer in besonder betref, is Stoker beslis van mening dat dit nie modaal bepaal is nie, maar dinamies. Sy argumente teen die historiese as modaliteit is veral die volgende:

a. Die historiese as sodanig is in verband met elke wetskring in dieselfde sin die historiese, en van modale fundering is hier geen sprake nie: die historiese staan in sy verband tot die dimensie van gebeurtenisse (die dinamiese) as ' $t$ ware loodreg op die dimensie van modaliteite. Daarom is 
dit willekeurig om die historiese in die modale rangorde 'n plek te gee: dit kon net so goed voor as ná die logiese, linguale, ens. gekom het. Dit is kunsmatig om die historiese êrens tussen die normatiewe modaliteite in te skuif en te sê dat in verband met die logiese (geskiedenis van denke) die historiese slegs retrosipasies bied, terwyl dit in verband met die taal antisipasies bied, hoewel die historiese in beide gevalle juis in dieselfde sin die historiese is.

b. Daar bestaan ook geskiedenis van individuele en sosiale strukture (biografieë, geskiedenis van volke, state, ens.) en geskiedenis is hier geskiedenis in presies dieselfde sin as met betrekking tot die modale (geskiedenis van denke, taal, kuns ens.). Die historiese staan dus as ' $t$ ware ook loodreg op die strukturele bepalings as sodanig in die kosmiese dimensie van individuele en sosiale strukture. Maar self verteenwoordig dit ook maar net 'n abstrakte dimensionele aspek. Die volle werklikheid van die mensheid, ook in sy dinamiek, is meer as histories. Anders sou ons in historisme verval.

Daar is verder ook die waarde-aspek wat altyd in gedagte gehou moet word. Daar is naamlik 'n goed-kwaad-bepaaldheid waaraan die hele kosmos deel het. Hierdie waarde-bepaaldheid is volgens Stoker iets anders as modale en strukturele en dinamiese bepaaldheid, hoewel dit daarin gefundeer is.

Die goed-kwaad- of waarde-bepaaldheid gaan vir ons oop eers wanneer iets werklik geskied; en dan sien ons dat hierdie gebeurtenisse al of nie beantwoord aan die wesensbepaaldheid en werklikheidsbestemming van die betrokke skepsele. Dit word beoordeel volgens modale wette, maar ook strukturele wette en teleologiese gesigspunte ens. Is daar, so gesien, afval, dan spreek ons van onwaarde, en omgekeerd van waarde. Nou moet die vakwetenskappe by alle dimensionele bepaaldheid steeds alle dimensies en die volle werklikheid in ag neem en so moet die historie-wetenskap ook die aksiologiese gesigspunt in rekening bring.

Hiermee is prof. Stoker se reaksies op die onderhawige materie beknop, maar taamlik omvattend weergegee. En ek voel geneig om hom in elk geval in sover teenoor Dooyeweerd by te val dat ek ook die historiewetenskap nie as 'n modaal bepaalde vakwetenskap sien nie. Die volle realiteitsdinamiek van die historie gaan daarmee teloor, soos reeds tevore deur my aangedui en deur Stoker beklemtoon. 
Hoe dit sy, dit is seker behartigingswaardig wat Dooyeweerd sê, nl. dat die geskiedwetenskap iets anders moet ondersoek a: slegs of alles wat gebeur het. Hy praat bv. van magsvorming en sosiale differensiëring en integrering ens., alles onder die deur hom veronderstelde historikale modaliteit van die werklikheid.

Vir my wil dit egter lyk of die geskiedwetenskap die menslike samelewing as geheel in sy sosiale differensiasie en integrasie, soos ondersoek deur die sosiologie en die sosiale vakwetenskappe, op die grondslag van die ongedifferensieerde oertoestand, soos bestudeer deur die etnologie ens., moet bestudeer onder ' $n$ bepaalde gesigspunt, wat deur die historii nog nie vasgestel is nie, hoewel Augustinus daar reeds van Christelike standpunt 'n aanduiding van gegee het.

Hierdie gesigspunt skyn my, op die grondslag van die algemene dinamiek van Stoker se gebeurtenisdimensie, dié te wees van vervulling van die aarde, en kultivering en vereniging daarvan by wyse van sosiale differensiasie en integrasie en deur middel van historiese magsvorming in die vorm van nasionaliteite en internasionale verbindinge. Hierby moet die besondere bydrae van bepaalde tydperke en kultuurkringe, van bepaalde rasse, nasies en leiers, van bepaalde modaal bepaalde samelewingsgroepe soos die juridiese, die ekonomiese ens. onderskei word soveel moontlik in tipiserende vorm.

In elk geval moet die historie-wetenskap die voortgang van die mensheid tot sy tydelike bestemming beskryf en verklaar, nl. tot die kulturele vereniging van die aarde. Tegelykertyd moet behandel word die ontwikkeling van die volheid van die tye in sy verskillende stadia met die oog op die koms en die wederkoms van Christus, die oorgang daarvan van geloof tot aanskouing binne die groeisel van die wêreldgeskiedenis deur die eeue.

Met die oog op so 'n geskiedwetenskap gee Dooyeweerd wel waardevolle abstrakte wenke bv. (behalwe wat reeds genoem is), dat die historisme as sodanig afgewys moet word omdat dit alle modaliteite vervlugtig, dat die historie nie tot die verlede beperk is nie, dat dit nie alles omvat wat gebeur het nie, moontlik dat dit eers aanvang wanneer die sosiale gebeure op een of ander manier gesimboliseer word, en nadat sosiale differensiëring ingetree het, dat dit verband hou met die kultuuropdrag aan die mensheid in Genesis, dat dit opereer deur beheersing van die omgewing, magsvorming, sosiale differensiëring en integrering, loswikkeling van die individualiteit; ens.; ook is interessant sy onderskeiding tussen kulturele subjek en objek, 
sy aanduiding van eersgenoemde ook as historievormer, sy onderskeiding tussen wetsaspek en subjeksaspek, en erkenning van die selfstandige normatiewe karakter van die historie die magsvorming oor persone as kenmerkend van die historie, hierdie mag gesien as roepingsmag, die tendens van die tradisie tot historiese kontinuitteit, die eie aard van historiese kousaliteit, die opvatting van kultuurontsluiting, die leiding hiervan deur latere wetskringe, ten slotte diè van die geloof, die noodsaaklikheid van 'n historiese ontwikkelingsidee wat sedert Ranke in verval geraak het, die historiese individualiseringsproses, ens., ens.

Maar sy opvatting van die historikale as ' $n$ blote modaliteit laat sy beskouinge $m$.i. in die lug sweef. Hiermee kom ons egter tot'n dieper kwessie, wat saamhang met die verskil tussen Dooyeweerd en Stoker waarmee ek begin het. Sonder om nou Stoker se waarde-leer te aanvaar, lyk dit my tog in hierdie verband of Stoker grond het vir sy beswaar teen Dooyeweerd c.s. dat hulle die konkrete werklikheid dreig te vervlugtig tot funksies, modaliteite, sin, tipiese strukture, wette met subjeksaspekte, ens. ens., en dat hulle die dinamiek en konkreetheid van die geskape werklikheid misken.

Dit is immers nie net, soos Stoker tereg sê, dat hulle die mens in die middelpunt stel i.p.v. God nie, maar hulle sentrale mens herinner nog baie aan Kant se bleekskimagtige noemenale wese, 'n soort kategorieë-kompleks -en in daardie lig verbleek die werklikheid tot 'n modaliteite-kompleks met tipies-strukturele subjeks-aspekte.

Vir my gevoel egter is primêr die werklike dinge en mense, stof, energie, bloed, lewe, drang en daad, en slegs sekundêr wyse van syn en struktuurtipes.

Daarom is die geskiedenis nie alles wat gebeur het nie, maar die beweging of ontwikkeling in die tyd van die mensheid tot sy eindbestemming en alles wat daartoe diensbaar is op die verskillende terreine van die samelewing.

En beslis sou ek in die wetenskaplike behandeling van die geskiedenis nie beperk wil wees tot 'n modaliteitstudie nie, en ook nie tot die studie van enige modaal bepaalde samelewingsvorm soos bv. die staat nie, maar die studie moet gerig wees op die konkrete mensheid as geheel in die progressiewe vervulling van sy kultuurtaak.

Daarby sou as die wêreldhistoriese epogale gebeurtenisse besondere aandag geskenk moet word aan skepping, sondvloed, Babelse verwarring, 
isolasie van Israel, eerste koms van Christus, verwestersing van die kultuur, botsing tussen wes en oos, totalitarisme en wêreldvereniging deur die moderne tegniek met die oog op die wederkoms in die volheid van die tye.

Hier word slegs 'n voorlopige aanduiding gegee. Moontlik kan dit vakkundiges prikkel om verdere uitwerking te gee aan wat eintlik die studieveld is van die geskiedwetenskap in onderskeiding van blote kroniekskrywery of 'n naturalistiese kringloopsbeskrywing van kulture.

In elk geval sal 'n Afrikaans-Christelike historicus seker besondere andag moet skenk aan die nasionaliteitsfaktor, iets wat veral die huidige Calvinistiese denkers van Nederland skromelik veronagsaam. Hulle staar hulle blind op die staat, hoewel hulle ook weer geneig is om die rol van die staat reaksionêr te minimiseer.

Van nasionaliteitstandpunt gesien is die wêreldhistoriese krisis van ons tyd daarin geleë of die komende wêreldeenheid internasionaal opgebou sal word op die nasionale verskeidenheid, dan of dit kosmopolities geuniformeer sal word op 'n klasse-egalitarisme.

Ook in hierdie opsig staan die westerse demokrasie teenoor die oosterse kommunisme, en Suid-Afrika, en meer bepaald die Afrikanerdom, se wêreldhistoriese rol is in hierdie verband om die weste weer bewus te maak van sy eie ideologiese grondslag teenoor die oosterse massale uniformisme, nl. dié van (internasionale) eenheid in (nasionale) verskeidenheid.

En hierdie nasionaliteitsfaktor staan of val nie met die staat nie: die nasionaliteit streef wel altyd om homself staatkundig af te rond; maar ook in 'n wêreldstaat sou nasionale verskeidenhede gehandhaaf kan word, en nie net op 'n ..folkloristiese" peil nie, soos Dooyeweerd c.s. skyn te meen. Die Nederlandse denkers se oppervlakkige kultuur-universalisme en hulle histories-bepaalde allergie teenoor veral die Duitse nasionalisme het hulle inderdaad ook in hierdie verband erbarmlik geestelik verarm gelukkig, egter meer in skyn as in werklikheid. Want ten slotte straal hul eie nasionale tipe tog altyd deur selfs in hulle vermeende kosmopolitisme!

\section{J. DU PLESSIS}

N.S.-'n Interessante nuwe geskiedenis-beskouing van Calvinistiese standpunt word gegee in F. Kuyper se „.Geloof en Wereldbeeld" (Wever, Franeken, 1956). wat ek egter in bostaande artikel nie kon assimileer nie.

L. J. du P. 